\title{
O CORPO CÔMICO FEMININO: \\ CONVENÇÕES, RENOVAÇÕES E PARADOXOS
}

\section{The female comic body: conventions, renovations and paradoxes}

\author{
Daniele Pimenta ${ }^{1}$ \\ Universidade Federal de Uberlândia - UFU
}

Resumo: Este artigo discute questões relacionadas à comicidade feminina, de modo a demonstrar o quanto essa vertente de atuação é rica e presente nas artes cênicas, embora a imagem cômica da mulher não tenha, ainda, dominado o imaginário de nosso público de forma equivalente à imagem sublime.

Palavras-chave: Corpo cômico; Atuação cômica; Feminino.

Abstract: This article discusses issues related to female comicity, in order to demonstrate how this aspect of performance is rich and present in the performing arts, although the comic image of women has not yet dominated the imagination of our audience in a way equivalent to the sublime image.

Keywords: Comic body; Comic performance; Womanly.

\footnotetext{
1 Docente do curso de Teatro e do PPGAC - Programa de Pós-graduação em Artes Cênicas da UFU. Também é atriz, diretora musical e coreógrafa da Cia. PICNIC de Teatro. Como pesquisadora, tem diversas publicações sobre CircoTeatro.
} 
A palavra "feminino" remete, para muitas pessoas, em um primeiro fluxo de ideias, a termos como delicadeza, suavidade, beleza, leveza, fragilidade. Para outras, "feminino" pode aludir a maternidade, sagrado, proteção, cuidado, sacrifício, abnegação. Temos ainda as possibilidades em torno dos conceitos de sensualidade, sedução e erotismo.

Como contraponto a essas imagens, há quem logo associe "feminino" a força, determinação, luta, independência, resistência, autonomia, seguindo tendências associadas à urgência de um movimento de renovação ou, melhor, de transformação ética de nossa sociedade.

Mas, é muito raro que "feminino" traga, de imediato, imagens e palavras do campo da comicidade!

A perspectiva sublime do feminino está enraizada em nossas mentes desde, provavelmente... sempre! Seria algo supostamente natural, ancestral, ou algo construído culturalmente ao longo de milênios de desenvolvimento de sociedades patriarcais? Ou a combinação de ambos?

Atualmente convivemos com o crescimento da luta por mudanças na perspectiva do que seja o feminino, dentro de uma luta mais ampla, que é a própria discussão de gêneros. Nesse contexto, convivemos com questões complexas e, por vezes, paradoxais.

No campo da atuação, enquanto, por exemplo, palhaças criticam, de forma mordaz e recorrente em suas dramaturgias, a opressão social que as força a usar salto alto, maquiagem, pintar cabelos e se depilar, as Drag Queens usam exatamente esses recursos para compor a figura feminina.

Este artigo, embora parta das questões ou das provocações acima, não pretende enveredar pelo campo antropológico, psicológico ou sócio-político, mas elencar algumas manifestações da comicidade feminina, as quais, é claro, trazem em forma e conteúdo, muitas dessas questões.

O propósito é reunir exemplos de expressões da comicidade feminina, de modo a demonstrar o quanto essa vertente de atuação é rica e presente, de forma muito frutífera, nas artes cênicas, embora a imagem cômica da mulher não tenha, ainda, dominado o imaginário de nosso público de forma equivalente à imagem sublime.

Assim como são diferentes as manifestações artísticas e as personalidades das artistas selecionadas, são diferentes os focos de análise: em alguns casos, o foco de análise estará centrado nas questões estéticas, em outros, em aspectos temáticos e, além dessas, alguns exemplos trarão também questões sociais.

\section{A caricata}

$\mathrm{Na}$ época de ouro do Circo-Teatro brasileiro, os circenses seguiam o sistema de organização teatral das companhias urbanas da passagem do século XIX para o $\mathrm{XX}$, com atores e atrizes especializados em papeis que são funções dramáticas. 
Atores que assumiam mais de um tipo de papel eram chamados de genéricos, mas as especializações eram, basicamente, a ingênua, o galã, a dama-galã, o cínico (vilão), o cômico e, no caso da atriz que assumia os papeis cômicos, a caricata.

A construção da caricata partia da combinação entre as características indicadas na dramaturgia textual e a personalidade da atriz que desempenharia o papel, além de aspectos físicos e vocais a serem ressaltados.

Destaco aqui dois exemplos de companhias de circo-teatro, atualmente em atividade, nos quais podemos ver a caricata em cena: o Circo-Teatro Guaraciaba e o Circo de Teatro do Tubinho, ambas do estado de São Paulo.

No caso do Guaraciaba, tive a oportunidade de assistir à montagem de ...E o céu uniu dois corações, de Antenor Pimenta, por ocasião das comemorações dos 70 anos da companhia. No espetáculo, além de Adélia, papel concebido originalmente para uma caricata, interpretado por Geisa Helena, atriz e palhaça, também atuante na Trupe Koskowski, temos a conversão do personagem Velasco para o feminino, ou seja, de cômico para caricata, para que se pudesse aproveitar a veia cômica da veterana atriz Edimeia Rocha.

Edimeia e Geisa tiveram formações e experiências muito diferentes, ao longo de suas trajetórias, em função, principalmente, da diferença de gerações. Entretanto, a companhia tem feito um trabalho de formação durante os processos de montagem de seus espetáculos, de modo a garantir um resultado coeso na união de atores jovens aos atores da chamada "velha guarda" do Guaraciaba.

Ambos os papeis têm, já na sua concepção textual, a base para as muitas gags verbais e corporais das personagens e das situações, e as atrizes compõem seus papeis recorrendo a recursos de seus próprios repertórios e temperamento, como apontado anteriormente.

Quanto à discussão sobre o conceito de feminino, o papel de Adélia está circunscrito a uma questão que depende do papel ser de uma mulher: a tentativa de se formalizar um acordo de casamento, entre Adélia e o jovem galã, Alberto, arranjado entre seu pai, Benevides, e o tutor do jovem (e grande vilão da trama), Della Torre. A comicidade de Geisa, além dos chistes e trocadilhos propostos pelo autor (Benevides é um português "das antigas" e sofre para entender as gírias "modernas" de sua filha), deve-se muito à sua construção corporal, que tem como base sua desenvoltura física, agilidade, força e flexibilidade, resultantes de sua formação em técnicas circenses.

Já o papel de Edimeia, Dona Velasca, foi escrito originalmente para um homem, Sr. Velasco, e o papel, embora situe-se em um contexto que não depende desse aspecto, ganha novas dimensões com a apropriação feita por Edimeia: o personagem é, originalmente, o dono do bar no qual se 
passa o primeiro ato. Todas as passagens cômicas estão relacionadas às confusões geradas em função de sua surdez, o que propicia momentos muito divertidos, a partir dos mal-entendidos com os demais personagens, sejam eles do núcleo do bem ou do mal. Porém, passando a ser feminina, a personagem muda conceitualmente um traço em sua composição: os cuidados maternais. É ela quem recebe a família de Nely, em desgraça em virtude dos acontecimentos que antecedem o início da peça, e fornece as refeições para que não pereçam.

Sendo mulher, o resultado cênico é transformado: parece ser mais "natural" que uma mulher os acolha, em uma atitude maternal. Em outras encenações a que assisti, o impacto gerado pela bondade do dono do bar parece mais heroico, pois o acolhimento sem cobranças parece mais justificável vindo de uma mulher do que de um homem.

Corporalmente, é interessante observar como Edimeia, apesar de ser uma atriz idosa, constrói sua caricata imprimindo ritmo e tônus diferentes dos seus naturais aos movimentos. A atriz trabalha com a consciência de que o papel vai além da aparência da idade e garante, com sua atuação, a sustentação do ritmo cênico nas passagens de alívio cômico.

O tempo preciso nas intervenções é conquistado pelo controle das movimentações, de forma que D. Velasca não prejudique a condução do foco da ação dramática, mas esteja exatamente no lugar certo, no momento certo, para quebrar o clima de tensão com suas colocações hilárias.

A forma de caminhar e gesticular garantem a dilatação necessária aos seus tempos de ação, para que o público se concentre no desenrolar da trama séria e seja surpreendido por suas divertidas intervenções.

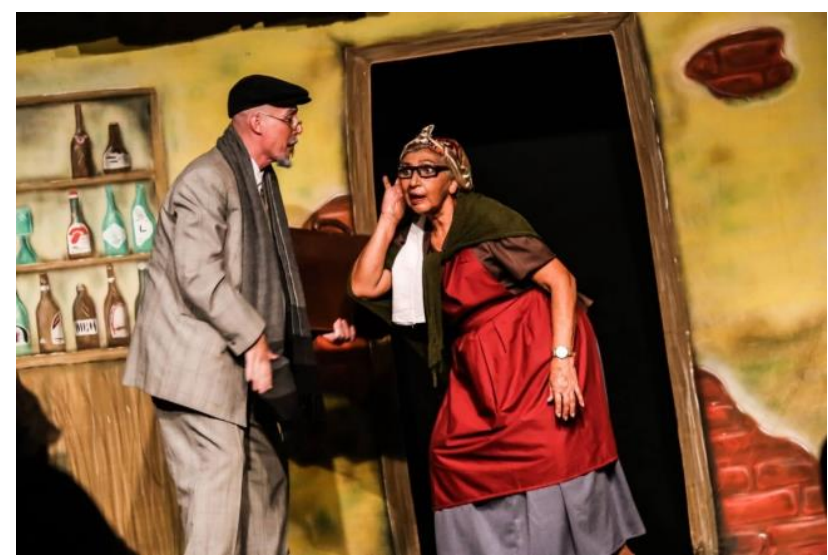

Edimeia Rocha e Guilherme Martelli, em ...E o céu uniu dois corações. ${ }^{2}$

Já a personagem de Geisa, Adélia, tem liberdade para explorar sua atuação cômica praticamente em todos os momentos em que está em cena.

As situações desenvolvidas a partir da estrutura da dupla cômica pai e filha vão do humor verbal ao corporal, construídos tanto pelas proposições do texto quanto pelo desempenho dos atores, que têm a diferença de idade muito bem aproveitada na dinâmica de cena.

Benevides é interpretado por Hudi Rocha, palhaço e ator muito experiente, também da velha guarda do Guaraciaba. Sua

\footnotetext{
2 Disponível em:

<https://www.facebook.com/circoteatroguaraciaba/photos/ a.1936087993304319.1073741836.1644574029122385/1 936092726637179/?type=3\&theater $>$. Acesso em 04/07/2018.
}

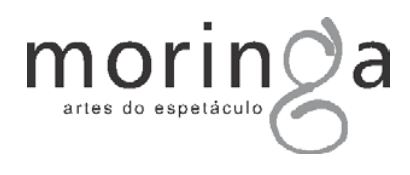


agilidade na construção dos "atrapalhamentos" do personagem permite compor contrapontos interessantes com a movimentação e construção corporal e vocal de Geisa Helena.

A atriz consegue compor uma personagem bonita e grotesca ao mesmo tempo. Usa a consciência de que tem um corpo atlético e bem condicionado, com domínio acrobático, para compor figuras inesperadas: desajeitadas e com pontos de equilíbrio fora do eixo.

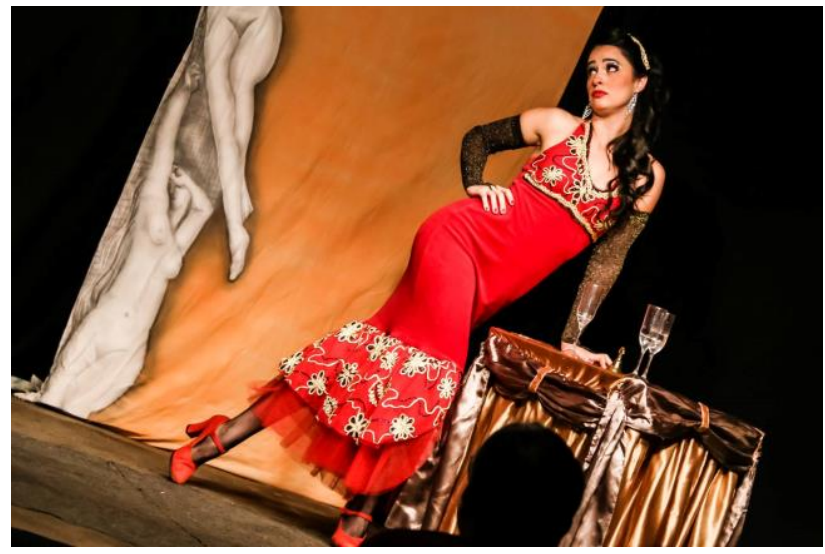

Geisa Helena em cena de ...E o céu uniu dois corações. ${ }^{3}$

No Circo de Teatro do Tubinho, companhia que encena prioritariamente comédias, os papeis femininos são construídos mais próximos da noção de palhaça do que de caricata.

A caracterização e a construção corporal e vocal são hiperbólicas e a movimentação apoia-se na inclusão de gags clássicas do repertório cômico circense, muito mais na linha das comédias de picadeiro do que

3 Disponível em:

<https://www.facebook.com/circoteatroguaraciaba/photos/ a.1936087993304319.1073741836.1644574029122385/1

$936110913302027 /$ ?type $=3 \&$ theater $>$. Acesso em 04/07/2018. nas altas comédias de palco do circoteatro.

A visão arrojada do tipo de protagonismo do palhaço Tubinho abre a possibilidade da atuação de palhaças, de forma a compor um todo coerente, diferentemente do que se encontrava nos anos 1970, em que, geralmente, o palhaço era o único a atuar caracterizado como tal, em um elenco constituído por atores "de cara limpa", como indica o jargão circense.

A construção corporal das mulheres no Circo de Teatro do Tubinho transita entre a tipificação e a palhaçada, ou seja, são palhaças que atuam de acordo com as funções das personagens concebidas no texto ou roteiro.

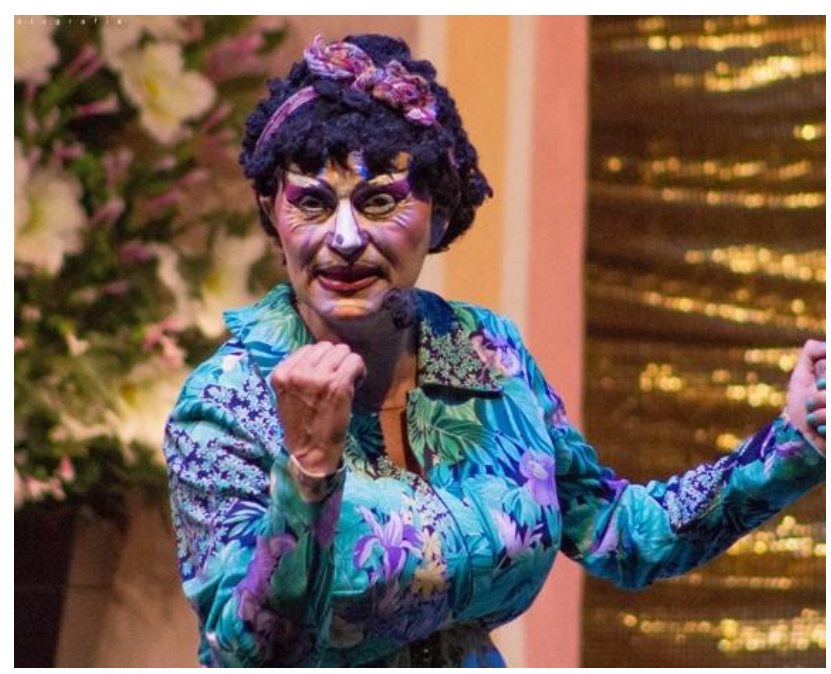

Ana Dolores em cena de Tubinho contra Lampião, o rei do cagaço. ${ }^{4}$

\section{Teatro de Revista}

A comicidade feminina no teatro de revista manifesta-se de diversas formas, tantas

\footnotetext{
${ }^{4}$ Disponível em:

$<$ https://www.tubinho.com.br/elenco.php $>$. Acesso em 04/07/2018.
}

Revista Moringa - Artes do Espetáculo, João Pessoa, UFPB, v. 9 n. 2, jul/dez 2018, p. 17 a 26

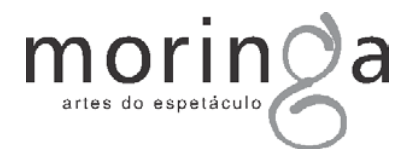


quantas são as possibilidades de abordagem do conceito de feminino no teatro ligeiro nas diferentes fases da revista.

A mulher está presente do coro às vedetes, passando pelos tipos tradicionais e pelos números de cortina.

A beleza e a sensualidade são uma armadilha para que 0 encantamento conduza à comicidade surpreendente dos trocadilhos e gestos picantes das vedetes, nas cenas e canções de double sens.

A comicidade feminina pode ir da leveza ao grotesco na construção das infinitas possibilidades de alegorias. Poderíamos, hoje, brincar com a crise da saúde pública escolhendo mostrar uma atriz como um escrachado mosquito que pica, pica ou como a doente febril cada vez mais quente!

A atriz do teatro de revista pode ir da construção corporal paródica à sensualidade poderosa e, ainda, brincar com os diferentes tipos brasileiros nas cenas da revista propriamente dita ou nos números de cortina.

O exemplo mais brilhante de atriz cômica revisteira é Dercy Gonçalves. A atriz virou sinônimo de deboche, criatividade e despudoramento, ao ponto de não sabermos o que é ficção e o que é realidade em suas aparições públicas.

O domínio do tempo cômico e a disposição para afastar-se do padrão feminino da beleza idealizada fizeram de Dercy um ícone da comicidade brasileira.
Segundo Virginia Maisano Namur:

Dercy não parodiava, no sentido estreito do termo, embora a paródia estilística também fosse um de seus apoios. Fazia muito mais: carnavalizava o teatro e a vida. Entregava-se a um hiper-realismo grotesco, rebaixador de qualquer ordem instituída, em especial a da nobre arte a que se filiava. Foi antivedete de revista e fez comédia da própria comédia burguesa, bem comportada. No cinema, foi cometa, não estrela. E na TV, sempre fez Dercy de Verdade. Em todo desafio encontrou uma saída. Deu asas ao disforme que extraiu da algaravia mal educada das ruas e fugiu de idealizações. Brincou em pleno trabalho e, pecado dos pecados, se divertiu e muito. (NAMUR, 2009, p. 246)

A atriz atravessou décadas atuando em diferentes meios - circo, teatro, cinema e televisão - e mantendo-se atual até o fim de sua vida.

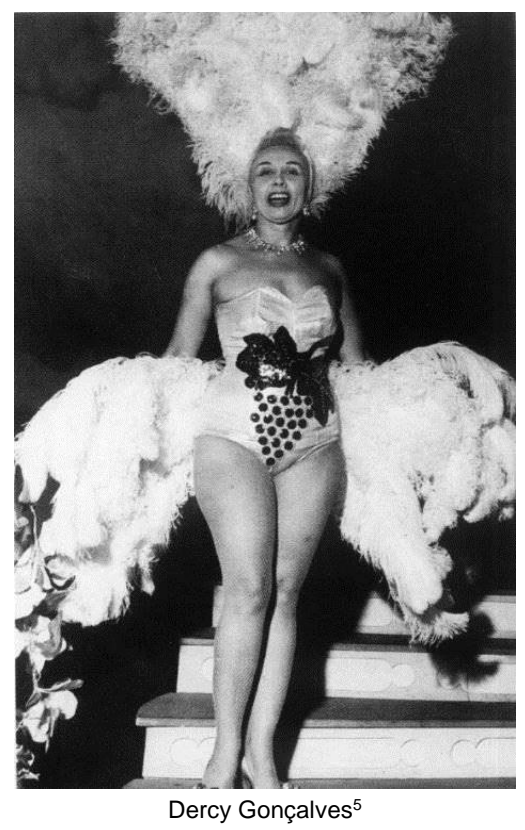

${ }^{5}$ Disponível em:

$<$ https://teatrobr.blogspot.com/2010/12/dercygoncalves.html>. Acessado em 04/07/2018. 


\section{Humor em quadros}

O universo do circo e da revista teve seus reflexos na dramaturgia radiofônica e televisiva.

A dramaturgia em quadros, a comicidade caricatural, a alternância entre momentos densos ou líricos e o humor desbragado, e a perpetuação de tipos levaram à elaboração de modelos de programas que se tornaram clássicos, a exemplo da Escolinha do Professor Raimundo e A Praça é Nossa.

A Escolinha segue o modelo de programas radiofônicos e a Praça é, claramente, filha das cenas de passagem da revista.

$\mathrm{Na}$ escolinha há várias atuações femininas memoráveis, como as de Zezé Macedo, Nélia Paula, Claudia Gimenes, Nadia Maria, Berta Loran, Fafy Siqueira, entre outras. Uma das mais notáveis é a de Zilda Cardoso, em sua personagem Catifunda.

A construção pauta-se pela oposição à percepção da feminilidade idealizada e padronizada, a do senso comum.

Catifunda está longe de ser delicada e sutil, assim como não envereda pela comicidade sensualizada.

Zilda Cardoso construiu uma das primeiras personagens a quebrar estereótipos de gênero na TV brasileira, sem, no entanto, fazer dessa discussão o seu mote: ela era assim, e pronto. Os temas variam, a atitude é que importa.
Catifunda é uma espécie de ilha de resistência entre estereótipos cômicos femininos da televisão, que costumam girar, de certa forma, em torno dos padrões de beleza: tornar risível a muito gorda ou a muito magra, assim como tornar risível a bonita-e-burra.

Catifunda é sagaz e destemida, a ponto de tomar como elemento de sua construção, quase como bordão visual, um charuto, em uma inteligente apropriação de um dos mais populares símbolos fálicos. O charuto, presente tanto no imaginário popular das salas de espera das maternidades quanto na referência de erudição pop Freudiana "às vezes um charuto é apenas um charuto!"-, passa das mãos para a boca de Catifunda, pontuando suas pausas e arremates, mas sem hipervalorização. 0 foco mantém-se nas suas atitudes e a manipulação do charuto é incorporada ao seu gestual como algo naturalizado pela personagem, algo que já faz sem pensar, algo que domina.

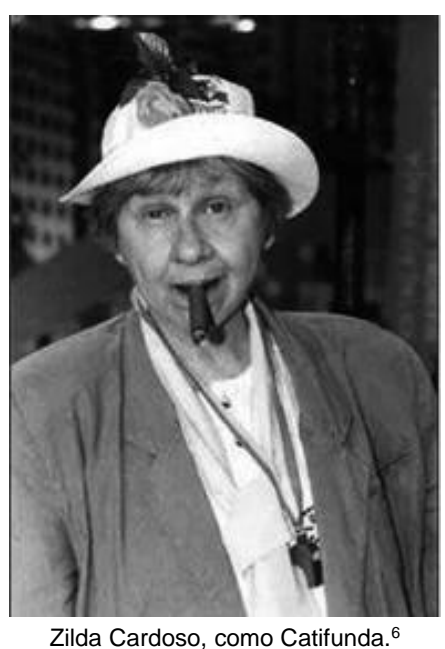

\footnotetext{
${ }^{6}$ Disponível em:

$<$ http://www.historiadocinemabrasileiro.com.br/zildacardoso/>. Acessado em 04/07/2018
} 


\section{Xamego}

Uma das personalidades mais significativas da comicidade feminina brasileira era desconhecida do público atual até bem recentemente.

Maria Eliza Alves dos Reis, nascida em 1909, criada no Circo Guarani, tornou-se o palhaço Xamego, por iniciativa própria e não sem dificuldades: como desafio inicial, precisou convencer seu pai, dono do circo, de que poderia assumir o lugar de seu tio, impedido de trabalhar por problemas de saúde.

Maria Eliza teve que atuar caracterizada como homem para poder assumir a função de palhaço. Precisou manter seu corpo velado, em parte pela percepção de que o palhaço seria especificamente um personagem masculino, em parte porque a atuação do palhaço circense pressupõe situações, gestos e atitudes impensáveis para uma mulher, naquela época: o baixo cômico, as quedas, a escatologia, um simples chute na bunda... nada disso condizia com o perfil feminino, no ambiente patriarcal do circo brasileiro, nas primeiras décadas do século XX.

A história de Xamego é contada no filme Minha vó era palhaço! dirigido por Mariana Gabriel, neta de Maria Eliza, e Ana Minehira.

O documentário traz muitas provocações e abre possibilidades de discussão sobre vários aspectos da situação da mulher, artística, política e socialmente.
Mulher, em um papel masculino; negra, em um universo artístico majoritariamente branco; Maria Eliza foi uma personalidade importante, que começa a ser descoberta e que, espero, passe a ser objeto de pesquisa também nas universidades.

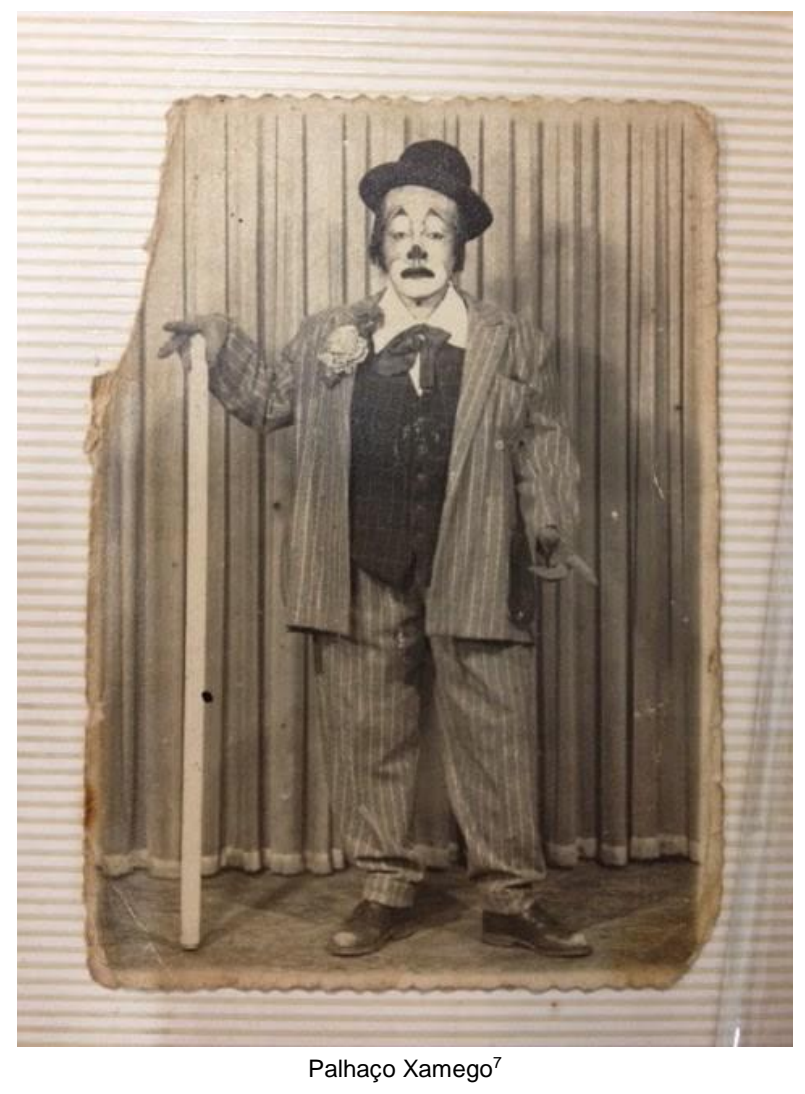

\section{Considerações (nada) finais}

A comicidade feminina tem muitos aspectos a serem abordados e preparar este texto apenas me provoca a querer avançar no tema. Há ainda inúmeras questões que merecem reflexão, tais como: as divertidíssimas paródias de mulheres, feitas por cômicos no teatro, no circo, no cinema e na televisão; a abordagem da mulher em versões animadas, como o

\footnotetext{
7 Disponível em:

<http://palhacoxamego.blogspot.com/2015/03/primeiraparte_21.html> Acesso em 04/07/2018.
} 
mamulengo e a Nega Maluca dos dançarinos de feiras; os papeis femininos feitos por homens, ao longo de toda a história das artes cênicas - e aqui a discussão vai muito além da comicidade.

Não esgotaremos $o$ assunto $e$ nem chegamos perto de levantar de quantas formas podemos discutir, analisar, correlacionar elementos da comicidade feminina ou, de quantas formas podemos discutir e analisar a atuação feminina ou, ainda, o próprio conceito de "feminino".

Em um mundo que se percebe como palco de batalhas diárias por espaço, visibilidade e representatividade, corpos femininos evidenciam-se e evidenciam temas que afetam a todos, e a comicidade permanece em sua função de nos fazer refletir de forma viva, vibrante e potente.

A atuação cômica nos traz muitos desafios técnicos corporais e vocais, tão diversos quanto são suas vertentes estéticas e suas formas de se relacionar com o público.

Corpos e vozes dinâmicos, ágeis, ricos em expressividades, capazes de transitar rapidamente de um tipo a outro, de uma máscara a outra, de uma cena musicada à declamação que instiga, provoca e emociona.

Corpos e vozes que ocupam seus espaços: do centro da praça às telas do cinema, do palco italiano aos clubes comunitários, da televisão aos sindicatos e portas das fábricas, do picadeiro à telinha do youtube.
A comicidade cumpre sua função de atrair, entreter, provocar, estimular, propagar-se, alimentar-se e alimentar, em uma antiquíssima relação de amor com o público. A atuação cômica pressupõe, assim, uma abertura para o mundo e para o que acontece a cada dia, constituindo-se em uma ferramenta crítica contundente.

Se, em muitas culturas, as mulheres tiveram que enfrentar lutas duríssimas, ao longo de milênios, pelo direito de atuar, no campo da comicidade ainda há obstáculos a serem vencidos.

No Brasil, o movimento de mulheres palhaças é um exemplo que nos chama a atenção e que tem se construído como um movimento de resistência política. É surpreendente o quanto ainda é necessário lutar para que a voz feminina seja ouvida e respeitada em um universo - até recentemente - masculino.

A dramaturgia desenvolvida por mulheres palhaças pode se somar ou se contrapor ao repertório tradicional da palhaçada circense, construído por homens. Dependendo do processo de criação das palhaças, o acesso a esse repertório tradicional pode ser motivador de novas proposições, de apropriações e transformações para que o universo feminino seja contemplado estética e tematicamente.

Há um grande potencial de absorção de recursos cômicos, testados ao longo de séculos de tradições cênicas, que não podem ser desprezados e que independem 
- ou podem vir a independer - de um referencial masculino para funcionar em cena. Há, também, um potencial infinito de criação de novos recursos cômicos, a partir da proposição de uma percepção feminina sobre a palhaçada.

Em muitos dos trabalhos de palhaças, aos quais pude acompanhar nos últimos anos, observei ainda a existência do protagonismo masculino. Esse paradoxo surge de uma tendência em valorizar a presença masculina, para expor e criticar situações de opressão sobre a mulher, mesmo que não haja homens em cena.

Palhaças construindo esquetes a partir dos problemas enfrentados no dia a dia em uma sociedade machista, por vezes as colocam em um papel de quem reage, o que nos remete imediatamente ao homem, tornado sujeito oculto dessa nova escrita.

Acredito que essa fase seja necessária, mas que em breve a dramaturgia da palhaçada feminina possa tornar a mulher protagonista plena de suas criações e, ainda, que a perspectiva feminina resulte na ampliação do repertório da palhaçada como um todo.

O corpo cômico feminino - seja das palhaças, comediantes, atrizes, drag queens, vedetes, caricatas - constrói-se em consonância e, ao mesmo tempo, em atrito com a sociedade, agindo sobre e reagindo a diferentes percepções do que seja o próprio conceito de feminino, em um movimento constante de ampliação de repertório e aprofundamento poético, sustentado pela potência do riso.
Recebido em:15/06/2018

Aceito em: 30/07/2018

\section{Referências Bibliográficas}

MINEHIRA, Ana; GABRIEL, Mariana. Minha vó era palhaço. Documentário cinematográfico. Funarte, São Paulo, 2016.

NAMUR, Virginia M. S. Maisano. Dercy Gonçalves: 0 corpo torto do teatro brasileiro. Tese (Orient. Neyde Veneziano). UNICAMP, Campinas, 2009.

PIMENTA, Daniele. Antenor Pimenta: Circo e Poesia - a vida do autor de ...E o céu uniu dois corações. Imprensa Oficial do Estado de São Paulo/Fundação Padre Anchieta, São Paulo, 2005.

PIMENTA, Daniele; SILVA, Daniel M.. Nossa, essa peça ainda agrada, hein? O Circo-Teatro Guaraciaba e o melodrama ... E o céu uniu dois corações. Rebento, № 7. UNESP, São Paulo, 2017.

VENEZIANO, Neyde. 0 teatro de revista no Brasil: dramaturgia e convenções. Editora da UNICAMP, Campinas, 1991. 